


\title{
Unamuno y Nietzsche o el Quijote contra Zaratustra
}

\section{Unamuno and Nietzsche or Quixote versus Zarathustra}

Jaime Vilarroig Martín

Universidad CEU Cardenal Herrera

\begin{abstract}
Resumen
El artículo presenta las distintas interpretaciones que se han dado acerca de la recepción de Friedrich Nietzsche por parte de Miguel de Unamuno. A continuación se estudian directamente las fuentes de dicha recepción, planteándose una hipótesis original. Después se presenta la figura de Nietzsche por parte de Unamuno y sus temas preferidos: el sobrehombre, el anticristianismo y el pangermanismo, la vuelta eterna y el afán de inmortalidad. Por último, se delinean algunas convergencias y divergencias entre ambos autores.
\end{abstract}

Palabras clave: Unamuno, Nietzsche, interpretación, vuelta eterna (EwigeWiederkunft), sobrehombre (Übermensch).

\section{Abstract:}

This paper offers various interpretations on Unamuno's reception of Nietzsche's philosophy. We study directly the sources of these reception, with an original hypothesis. After that, a figure of Nietzsche is drawn, attending to Unamuno's point of view and 
his favorite subjects like: Übermensch, anticristianism, pangermanism, EwigeWiederkunft, and the will of immortality. Finally, we'll point on some convergences and divergences between both authors.

Keywords: Unamuno, Nietzsche, Interpretation, EwigeWiederkunft, Übermensch.

\section{Introducción}

$A_{\text {je de las interpretaciones nos impiden ver el bosque de lo que }}^{\text {menudo, en los estudios de comparación entre autores, el folla- }}$ quiso ser dicho. Porque aquí no se trata sólo de lo que dijo Nietzsche, ni de lo que Unamuno dice de Nietzsche, ni siquiera de lo que algunos dijeron que decía Unamuno de Nietzsche, sino de lo que el que escribe dice de lo que dijeron algunos que decía Unamuno de Nietzsche. Añada el lector otro grado más en esta potenciación de interpretaciones. Y así, es claro, perdemos de vista lo que se pretendía decir.

Entonces, ¿para qué comparamos autores trazando la historia de la recepción? En primer lugar porque, siguiendo a Gadamer, pensamos que no se puede acceder a la comprensión pura de un autor pasado sin tener en cuenta la pátina interpretativa que el paso de los años ha ido dejando sobre él. Tal pátina no sólo empaña, sino que es condición indispensable para acceder al pensamiento original del autor. Además, comparamos autores porque así esclarecemos mejor su pensamiento. Comparar autores estableciendo relaciones de filiación (o bien ideas resaltando afinidades y divergencias) esclarece la comprensión. Pero no olvidemos que en el bosque de las interpretaciones no podemos perder de vista lo que quiso ser pensado; volver a las cosas mismas, que pedía Husserl.

Nietzsche, ¿¿de qué habla? De la vida. Unamuno, ¿de qué habla? De la vida igualmente. Tanto lo que dice uno como lo que dice el 
otro, aluden a la realidad radical que dijo Ortega. Esto es lo que no podemos perder de vista en el bosque de las interpretaciones. Y puesto que la vida no es una cosa (y por tanto no se deja definir) ni es algo que esté ahí dado (y por tanto no se deja intuir), quizá haya que buscar, en la línea de lo que sugería García Morente (1938), símbolos desde los cuales dicha vida pueda ser pensada. En este caso, los símbolos no los tenemos que inventar, sino que vienen dados por los mismos autores que estudiamos: si Zaratustra es el personaje que mejor simboliza el intento de aprehensión de la vida por parte de Nietzsche, don Quijote es el personaje que hace lo propio en Unamuno.

¿Qué se ha dicho de la relación entre Unamuno y Nietzsche? La relación entre estos autores, al ser un tema muy especializado, cuenta con una bibliografía relativamente escasa (aunque no deja de sorprender la cantidad de estudiosos que se han fijado en el problema, como enseguida veremos); por ello, sólo se ha podido contar con los principales que tienen que decir algo relevante en este campo.

Para unos Unamuno ve en Nietzsche a un modernista más atacado de anticristianismo (Sobejano, 1967: 68-72, 279, 137, $312,133,124)$; sin embargo hay quien intenta una comparación sincrónica de ambos autores (Lavoie, 1976: 105-118) o apuntar importantes diferencias y cambios de perspectivas desde una consideración diacrónica (Ribas, 1987: 251-282; Mendoza, 1983: 5981); otras líneas se interesan en la visión trágica de ambos autores (González, 1986: 13-40) (Cordero, 2003: 13-28) o en destacar sus afinidades biográficas (Tamayo, 2000: 617-631). No obstante, en todos estos trabajos se nota una labor de sucesiva profundización en los temas (Gillis, 2008: 45-57). Y, aunque en todas estas comparaciones se hace hincapié en los aspectos biográficos que aquí no tendremos en cuenta. Ante esta proliferación de interpretaciones, demos un paso atrás en esta historia efectual (Wirkungsgeschichte) 
y preguntémonos: ¿qué sabía Unamuno acerca de Nietzsche? Para responder a esta pregunta, vamos a centrarnos en lo que leyó el rector de Salamanca del pensador alemán.

\section{Unamuno, lector de Nietzsche. Nuevas evidencias textuales y una hipótesis}

\subsection{Lecturas de y sobre Nietzsche antes de 1930}

Uno de los primeros testimonios sobre la lectura de Nietzsche por parte de Unamuno está asentado en su cátedra de Salamanca, poco antes de la crisis de 1897. En una carta a su amigo Múgica de 1896, Unamuno le dice que está leyendo a Nietzsche y a otros "anarquistas trascendentales" (Fernández, 1972: 218). Enseguida veremos que a Nietzsche no lo leía directamente, pues confiesa que durante mucho tiempo no había podido leerlo, sin embargo, en 1915 se encuentra con suficiente conocimiento como para escribir un artículo sobre él (Unamuno, 1915).

Una constante de Unamuno es la reiterada declaración de que no conoce a Nietzsche y que apenas lo ha leído, lo cual no le impide acabar formándose un juicio acerca del autor alemán, como veremos más adelante. Por ejemplo, en una carta a José de la Luz León (1928), dice: "Ahora no tengo aquí ni Heine, ni Schopenhauer, ni Nietzsche. A este le he leído poco, poquísimo, casi nada. Le conozco sobre todo por citas y referencias. Deseo leerle por entero; no sé cuándo lo haré” (Unamuno, 2012: 266). Esta carta está datada el 6 de septiembre de 1928. ¿Qué quiere decir esto? Que a los 64 años de edad, desde el destierro, Unamuno reconoce que aún no ha leído directamente a Nietzsche: sólo lo conoce por "citas y referencias". Sin embargo, no parece del todo cierto, puesto que 
el artículo "Para qué escribir" (Unamuno, 1919) es un comentario al epistolario inédito de Nietzsche, que trataremos luego.

¿Qué libros de y sobre Nietzsche existían en la casa de Unamuno antes del destierro (1924), de los cuales éste habría sacado su conocimiento fragmentario sobre Nietzsche? Libros de la autoría del alemán no parece que hubiera ninguno. Ahora bien, en la Biblioteca de la Casa Museo de Unamuno en Salamanca encontramos tres libros sobre Nietzsche que por las fechas de edición podrían estar perfectamente en la biblioteca del rector antes de su exilio: los de de A. Torre Ruiz, G. Brandes y M. A. Barrenechea.

El primero y más interesante es un libro de 1907, de A. Torre Ruiz, titulado Federico Nietzsche. El libro está dedicado por el autor "Al maestro de la juventud espańola, D. Miguel de Unamuno", lo cual demuestra la cercanía que los contemporáneos veían entre el pensador vasco y el pensador alemán. El libro cita a Lichtenberger, que es uno de los autores por los que Unamuno conocía a Nietzsche, según cuenta el propio Unamuno en Algo sobre Nietzsche (Unamuno, 1915). Este libro de A. Torre sin duda fue leído por Unamuno. ¿Cómo se demuestra? Porque lo único que le interesó a Unamuno de aquel libro fueron las faltas de ortografía que encontraba al paso de su lectura y que se preocupó de subrayar minuciosamente. Cosas de filólogos.

Los otros dos libros que presumiblemente tenía Unamuno sobre Nietzsche, previos al exilio, son menos interesantes porque Unamuno no parece que los leyera. El primero es de 1914, de G. Brandes: Essais Choisis, Renan, Taine, Niezsche, Heine, Kielland, Ibsen. Recordemos que Brandes fue uno de los que le descubrieron a Unamuno la raíz kierkegardiana de los dramas ibsenianos. Sin embargo, aunque otros ensayos del libro aparecen subrayados por Unamuno, el ensayo dedicado a Nietzsche (subtitulado "Un ensayo sobre el radicalismo aristocrático”) no lo está: razón por la cual nos inclinamos a pensar que no lo leyó. Esto es más evidente 
aún con el tercer libro de 1915, antes del destierro, Ensayo sobre Federico Nietzsche, de M. A. Barrenechea, el cual no sólo no tiene las acostumbradas notas al margen de Unamuno, sino que a partir de la página 135, los folios no están siquiera cortados.

Por otro lado, el libro de Nietzsche que más lee y profundiza Unamuno es sin duda su Epistolario inédito, en traducción española, y que comenta en un artículo de 1919 arriba citado ("Para qué escribir"). Conocida es la epistolomanía unamuniana, de ahí su interés por la correspondencia ajena, pues en su opinión este género literario es unas de las claves de acceso a la interioridad de una persona. Dejando de lado los parágrafos que más tienen que ver con literatura y estética, Unamuno reseña varias páginas: una sobre la necesidad de amigos íntimos y el disgusto de las opiniones en masa, otra sobre la incapacidad de la fe subjetiva para tener apoyaturas objetivas, otra sobre el genio literario y su influencia de Schopenhauer, otra sobre la amistad de los hombres solitarios, una muy interesante contra el nacionalismo prusiano y otra negando animadversión al cristianismo, pero reconociendo la imposibilidad de ajustarse a sus ideales (Nietzsche, 1919: 19-23, 24, 49, 67, 92, 180).

Ha quedado demostrado, pues, que en 1928 Unamuno aún no había leído a Nietzsche sino de segunda mano y por referencias, salvo el breve epistolario que acabamos de comentar. Además, en esa misma época expresaba su "deseo leerle por entero; no sé cuándo lo haré”. La principal hipótesis que vamos a lanzar aquí es que Unamuno leyó traducciones francesas de los libros de Nietzsche a partir de los años 30. Las evidencias se basan en los libros encontrados en la Casa-Museo del rector, pertenecientes al fondo de la biblioteca de Quiroga, yerno de Unamuno. 


\subsection{Lecturas de y sobre Nietzsche a partir de 1930}

Aunque los libros que vamos a citar ahora pertenecían a Quiroga, hay algunos que tienen anotaciones en los márgenes. Estas anotaciones coinciden al parecer con la caligrafía de Unamuno (a falta de un informe pericial), pero sobre todo coinciden con el método que éste tenía de anotar los libros: líneas a lápiz en los márgenes y en la última página anotaciones con las páginas en las que había algo subrayado. Los libros están casi todos comprados en Madrid, supuestamente por Quiroga, durante o inmediatamente antes del destierro, (puede conocerse esto por las anotaciones de Quiroga en las primeras páginas). Así que nuestra hipótesis es que Unamuno leyó estas obras prestadas por su yerno al volver del destierro, a partir de 1930.

¿De qué libros se trata? Se trata de un libro de S. Zweig sobre Nietzsche y de libros del propio Nietzsche: Asi habló Zaratustra, Ecce homo, un Epistolario inédito (el cual ya conocía o tenía en posesión en 1919, como hemos dicho) y un libro de aforismos sueltos.

Del libro en francés de S. Zweig, Le combatavec le démon, únicamente hay una anotación de Unamuno sobre el nacionalismo (Zweig, 1930: 166). De un libro con varios aforismos de Nietzsche, Unamuno subraya el pasaje de Así habló Zaratustra que comienza: "Yo os muestro al superhombre..." (Nietzsche, 1923). Del libro Así habló Zaratustra, que leyó igualmente en estos años, anota dos párrafos: el primero de la quinta parte del "Prólogo", cuya traducción reza: "Yo os digo: es preciso tener todavía caos dentro de sí para poder dar a luz una estrella danzarina. Yo os digo: vosotros tenéis todavía caos dentro de vosotros" (Nietzsche, 1921: 18); el segundo texto, en el capítulo titulado "Del pálido criminal", dice la traducción: "Vuestro matar, jueces, debe ser compa- 
sión y no venganza. ¡Y mientras matáis, cuidad de que vosotros mismos justifiquéis la vida!”.

También, en el ejemplar del Ecce homo que poseía en francés, Unamuno anota aquellos pasajes que le llaman la atención. En la parte quinta de "Por qué soy tan sabio", aparece un largo párrafo subrayado, que en parte dice "A quienes callan les faltan casi siempre finura y gentileza de corazón; callar es una objeción, tragarse las cosas produce necesariamente un mal carácter, estropea incluso el estómago. Todos los que se callan son dispépticos" (Nietzsche, 1921: 31). En el tercer párrafo de "Por qué soy tan inteligente", anota y dice la traducción: "En el fondo yo retorno una y otra vez a un pequeño número de franceses antiguos: creo únicamente en la cultura francesa y considero un malentendido todo lo demás que en Europa se autodenomina "cultura", para no hablar de la cultura alemana" (52). Finalmente, en la parte de "Por qué escribo tan buenos libros", en la sección quinta, subraya y dice: “¿Se ha tenido oídos para escuchar mi definición del amor? Es la única digna de un filósofo. Amor, en sus medios la guerra, en su fondo el odio mortal de los sexos. ¿ Se ha oído mi respuesta a la pregunta sobre cómo se cura a una mujer, sobre cómo se la «redime»? Se le hace un hijo" (58).

En conclusión, podría afirmarse que antes del destierro, según su propio testimonio y por evidencia documental, Unamuno había leído de segunda mano a Nietzsche, menos un epistolario. También había leído al menos un libro sobre Nietzsche (Torre Ruiz, 1907), sin interesarle demasiado. Pero después del destierro, según testimonio de Felisa de Unamuno (como apunta P. Ribas en el trabajo ya citado) y la evidencia documental que se constata en la biblioteca del autor en Salamanca, lee de Nietzsche un libro de aforismos, Asi habló Zaratustra y Ecce homo. Con todo, sigue siendo escaso el volumen de lecturas Nietzscheanas para hacerse 
una idea cabal del pensador alemán. ¿Y qué idea tenía Unamuno de Nietzsche? Vamos a verlo.

\section{El Nietzsche de Unamuno}

Para acercarnos a la idea que Unamuno tiene de Nietzsche y su pensamiento presentaremos cuatro tipos de texto: diario personal, artículo, ensayo y poesía. En primer lugar, un testimonio inicial de la influencia de Nietzsche sobre Unamuno en el Diario íntimo y el concepto de sobrehombre. En segundo lugar, dos artículos que Unamuno dedicó con cierta atención a Nietzsche y su pangermanismo y anticristianismo. En tercer lugar, recogeremos los parágrafos de Del sentimiento trágico de la vida donde el rector de Salamanca habla del atormentado filólogo, su afán de inmortalidad y la vuelta eterna. Por último, comentaremos la poesía que Unamuno dedica a Nietzsche y que resume muy bien todo lo anterior.

No respetamos el orden cronológico, puesto que los artículos (1915 y 1919) son posteriores al poema (1910). Sin embargo, esto no afecta la sustancia del asunto, puesto que las opiniones que recogemos aquí de Unamuno sobre Nietzsche son todas anteriores a 1930, cuando no conocía bien la obra del pensador alemán. Se trata, pues, del Nietzsche de Unamuno (en el más hondo sentido de la palabra). Y si hubiéramos de ser fieles al pensamiento del sabio rector, deberíamos prestar más atención a este Nietzsche que al histórico (su Vida de don Quijote y Sancho es un comentario extenso a esta idea: importa más el personaje de ficción que la persona histórica).

\subsection{El sobrehombre en el Diario intimo}

Hoy en día conocemos las circunstancias de este pequeño escrito unamuniano, oculto a la crítica durante largos años. Se trata de 
los apuntes que el atormentado rector fue anotando a raíz de las crisis que tuvo en 1897, por eso los problemas de interpretación de este pequeńo texto apenas comienzan ahora a resolverse (González, 2012). De nuestro tema, destaca en las páginas de este diario la insistencia sobre el superhombre (o sobrehombre, como traducirá siempre Unamuno). En el diario se relaciona, por ejemplo, el sobrehombre con lo sobrenatural, con el reino de la gracia: "Morir en Cristo es confundirse con los demás y llegar al toque de alma a alma. Y todo aquello del sobre-hombre en la sobre-naturaleza, ¿qué es más que una visión de la gloria, del bienaventurado reino de la gracia eterna?” (Unamuno, 2005: 267). Unamuno piensa que el verdadero sobrehombre es el cristiano: "El sobre-hombre, Uebermensch [sic]. Es el cristiano. 'Sed perfectos como vuestro Padre celestial'. El pobre inventor del sobrehombre está idiota, nuevo Nabucodonosor. El naturalismo acaba por el endiosamiento, por el único de Max Stirner; el sobrehombre de Nietzsche acaba en el nihilismo. Yoísmo y nihilismo son cosas que acaban por identificarse" (295); incluso insinúa que toda esta doctrina se encuentra ya en San Pablo: "El Ueber-mensch. El sobre-hombre es el cristiano, el nuevo Adán. Toda la doctrina del sobre-hombre se encuentra en san Pablo. 'Con Cristo estoy juntamente crucificado, y vivo, no ya yo, mas Cristo en mí” (369).

A la propuesta nietzscheana del sobrehombre, Unamuno responde (inspirándose en un pasaje del Kempis) con una propuesta propia: el intra-hombre, porque según él, Dios no habita fuera o por encima de nosotros, sino dentro de nosotros: "Uebermensch 'Pero porque pocos trabajan en mirar perfectamente a sí mismos, y no salen enteramente de su propio amor, por eso se quedan envueltos en sus afectos, y no se pueden levantar sobre sí en espíritu' (Imitación III, LIII, 3). No el sobrehombre, el intra-hombre hay que buscar, porque no sobre nosotros, sino dentro de nosotros habita Dios” (Unamuno, 2005: 374). El rector de Salamanca escribe aquí 
fuertemente inspirado por la crisis religiosa que estaba pasando en ese momento. Conviene notar, sin embargo, que una vez calmadas las aguas turbulentas de su espíritu, retomará el tema del intrahombre, el cual quedará como uno de los hitos fundamentales de su pensamiento. Véase, por ejemplo, el ensayo titulado "Adentro" (Unamuno, 2007), donde la fórmula es: no ¡adelante!, ni ¡arriba!, sino jadentro!

No obstante, en el Diario intimo tiene también una nota crítica hacia el concepto de sobrehombre nietzscheano: si el éste es aquel que aguanta estoicamente las calamidades de la vida, y saca fuerzas de flaqueza para crecerse en las situaciones de menesterosidad, el sobrehombre de Unamuno, el cristiano, es el que abraza y goza en los males y dificultades de esta tierra. Esto es lo sobre-humano: "La sabiduría humana llegó hasta el estoicismo (en cuanto se confunde con el epicureísmo) a sufrir indiferente los males terrenos, el abrazarlos y gozarse en ellos y amarlos es ya sobre-humano" (Unamuno, 2005: 392). Aunque el nombre de Nietzsche no aparezca en este texto, el guion en la palabra sobre-humano es suficientemente significativo para saber de quién está hablando.

\subsection{El supuesto pangermanismo y anticristianismo de Nietzsche}

Unamuno escribió al menos dos artículos dedicados a Nietzsche. El más temprano se titula "Algo sobre Nietzsche" (1915), donde comenta un reciente libro de Louis Bertrand, que alimenta la visión de un Nietzsche nacionalsocialista. Dice Unamuno que le sucedió como a Betrand, el cual intentó leer el Zaratustra pero lo tuvo que cerrar, "detenido por los matorrales de aquella mala prosa alemana”. Además de esto, no lo ha leído porque Nietzsche hiere los sentimientos de los pueblos cristianos: "El anticristianismo de Nietzsche, debo declararlo, me era y me es profundamente antipático. Me parece como todo anticristianismo de un hombre culto 
moderno, una verdadera hipocresía. Porque los hombres cultos de hoy somos todos hijos de una secular civilización cristiana y llevamos el cristianismo, querámoslo o no, a sabiendas o sin saberlo, en el meollo del alma”. Por todo ello, Unamuno prefirió ir a las fuentes del mismo Nietzsche, como L. Feuerbach.

El tema de la locura planea en todo el artículo (como vimos en uno de los textos del diario): "El pobre Nietzsche, que fue siempre lo que acabó siendo a las claras, un loco de remate"; y al libro Ecce homo le llama "portento de locura" (aunque ya hemos demostrado que por aquella época seguramente aún no había leído el libro). Para Unamuno, en el fondo, Nietzsche sería un envidioso (de Wagner, de Cristo)... Un hombre débil que para defenderse y vengarse de su debilidad exaltaba la fuerza. Por eso su manía fue predicar la violencia y se convirtió en apóstol del pangermanismo. Esta última opinión evidencia dos cosas: que Unamuno no había leído afondo a Nietzsche y que habla de lo que dicen otros de Nietzsche. Al fin y al cabo, Bertrand lo propone como prototipo del alemán guerrero. Afirma Unamuno que "Nietzsche era un pedante y ha hecho toda una legión de pedantes, pedantes de violencia, pedantes del amor desenfrenado a la vida, pedantes de anticristianismo" (Unamuno, 1915).

Si es cierta esta imagen de Nietzsche, se pregunta Unamuno, ¿Cómo es posible que haya engañado a tantos? Blasfemando de Cristo y el cristianismo. Muchos han buscado y leído a Nietzsche por anticristiano, no por literato ni por filósofo; sólo que se trata de un anticristianismo poco avisado: los que leen a Nietzsche son católicos que no han leído el Evangelio. Por ello, "quien cree no dejarse engańar por Cristo se deja engańar por un Nietzsche cualquiera" (1915). Y concluye con una frase lapidaria en la que resuena casi por entero, anticipándolo en casi dos décadas, el argumento de San Manuel Bueno: "Desgraciado el pueblo al que no le 
dejan soñar con los ojos puestos en el cielo de la noche y morando más allá de las últimas estrellas" (1915).

El segundo artículo en el que Unamuno trata con detenimiento a Nietzsche se titula "Para qué escribir", y lo redacta a propósito del Epistolario inédito de Nietzsche (Unamuno, 1919), que es el único libro del autor alemán que nos consta con certeza que leyó antes de 1930. Ya hemos dicho algunas palabras a propósito de la lectura por parte de Unamuno de este libro. Esta es, seguramente, la primera vez que Unamuno lee algo directamente de Nietzsche, pues en el artículo, el rector vuelve a confesar que conoce a Nietzsche de segunda y tercera mano, por fuentes no siempre de fiar. Sin embargo, en este artículo tiene alguna palabra, si no elogiosa de Nietzsche, sí al menos más benigna que en el artículo anterior. Y, aunque aquí también llama a Nietzsche hipócrita y actor, reconoce en él a un gran aislado que se siente solo en la cima (¿o en la sima?) irrespirable. Por eso, se detiene especialmente en la carta de Nietzsche a Rohde, del 22 de Febrero de 1884, donde habla de la soledad en la que le dejan los amigos, y que habla por no callar. Unamuno corrige esto de hablar por no callar y dice que se habla también para no oírse. Es evidente que el rector de Salamanca sabía bien de esto, dada su grafomanía.

En esta misma carta, Nietzsche se confiesa poeta, que es lo que siempre fue, lo cual merece la alabanza del rector: "Y verdadero poeta, no coplero, no orador en verso [...] Y por eso se ha tardado tanto en entenderle y se le entiende tan mal, sobre todo por sus compatriotas" (1919). Unamuno cae en la cuenta del malentendido sobre Nietzsche, y entrevé que quizá tiene con él más cosas en común de las que pensaba: "Tropezar con un hombre es doloroso, porque un hombre, no un mero escritor, es un espejo, y un espejo nos obliga a vernos, a ver nuestro hombre -iEcce homo!- a oírnos, ¡y es tan doloroso oírse!” (1919). Sin embargo, el malentendido 
sólo se da apropósito del pangermanismo, pero no en sus juicios sobre el anticristianismo.

\subsection{La vuelta eterna en El sentimiento trágico de la vida}

En El sentimiento trágico de la vida (1912) aparece citado el pensador alemán hasta seis veces. En primer lugar, Unamuno pone a Nietzsche junto a Tolstoi como las dos grandes víctimas del siglo crítico. Lo propio de este siglo ha sido el racionalismo a ultranza, que trata de racionalizar lo irracional, a la vez que irracionalizar lo racional: de ahí su desesperación: "Y en este siglo crítico, Don Quijote, que se ha contaminado de criticismo también, tiene que arremeter contra sí mismo, víctima de intelectualismo y de sentimentalismo, y que cuando quiere ser más espontáneo, más afectado aparece. Y quiere el pobre racionalizar lo irracional e irracionalizar lo racional. Y cae en la desesperación íntima del siglo crítico de que fueron las dos más grandes víctimas Nietzsche y Tolstoi” (Unamuno, 2005: 513). Recordemos que en los años en que escribe esto Unamuno, Nietzsche había muerto, habiendo sucumbido antes a una profunda locura.

Sin embargo, lo que más llama la atención al pensador vasco sobre Nietzsche es, sin duda, su filosofema del eterno retorno, o como prefiere traducir: la "vuelta eterna". Para Unamuno, siguiendo su peculiar hermenéutica de acercar a los autores a sus propias posiciones, lo que esta "eterna vuelta" manifiesta no es sino el afán de inmortalidad encarnada: una inmortalidad que no se contenta con existir siempre en un alma o cielo desvaídos, sino que quiere inmortalidad en esta carne y en este mundo (Unamuno, 2005: 396). Además, conoce perfectamente que la hipótesis de Nietzsche se basa en un mundo finito pero eterno, pues sólo en un universo finito y eterno pueden repetirse infinitas veces las mismas combinaciones (405). 
En un parágrafo extenso de El Sentimiento trágico, Unamuno se detiene a considerar a Nietzsche y la doctrina del eterno retorno (233-234). Además de llamarle "rebelde" y "fingido hipócrita", analiza el remedio "matemático" a la inmortalidad que propone. Sin embargo, dice Unamuno, es tan inconcebible una eternidad de tiempo (como propone Nietzsche) como una eternidad de espacio (cosas ambas que parecen confirmadas por la actual cosmología, añadiríamos). Por todo ello, declara a la teoría nietzscheana una "broma", y dice que el león de Nietzsche, el que aparece en la primera parte de Así habló Zaratustra, se ríe "de rabia, porque no acaba de consolarle eso de que ha sido ya el mismo león antes y que volverá a serlo" (234).

No obstante, a pesar de que el "remedio" a la mortalidad que propone Nietzsche no satisface, su propuesta misma es significativa. Y lo es porque, dice Unamuno, al fin y al cabo, tampoco Nietzsche se resigna a morir del todo. El pensador alemán, como todos, tenía corazón, sentimientos y hambre loca de inmortalidad (234-235). No era, en contra de lo que dejan traslucir muchos de sus críticos, un hombre que se contentara con su finitud, que asumiera el volver a la nada alegremente, como un destino inexorable pero vivible serenamente (160). También Nietzsche se resistía a morir, y quería vivir para siempre.

\subsection{Nietzsche poetizado}

Se ha dicho que lo mejor de Unamuno está en su poesía. En el oficio de poeta-creador es donde condensa lo mejor de sus reflexiones. Aunque, de nuevo recordamos que según la teoría unamuniana de la ficción, importa poco que el Nietzsche aquí poetizado se corresponda o no con el real, este soneto condensa la visión que Unamuno tiene de Nietzsche, al menos en la fecha en que fue escrito (1911): 
A Nietzsche:

$\mathrm{Al}$ no poder ser Cristo, maldijiste

de Cristo, el sobre-hombre en arquetipo;

hambre de eternidad fue todo el hipo

de tu pobre alma, hasta la muerte triste.

A tu atribulado corazón le diste

la vuelta eterna, así queriendo el cipo

de ultratumba romper ¡oh nuevo Edipo!

víctima de la Esfinje [sic] a que creíste

vencer. Sintiéndote por dentro esclavo

dominación cantaste, y fue lamento

lo que la risa sonó de león bravo;

luchaste con el hado en turbulento

querer durar, para morir al cabo

libre de la razón, nuestro tormento.

"Al no poder ser Cristo, maldijiste de Cristo". Nietzsche nos habla de un Nietzsche envidioso de Cristo, que por no alcanzar la talla humano-divina que propone reniega de él. Recordemos que Unamuno había hablado en otros momentos del ansia de ser Dios (¿envidia de Dios?), sólo que en Unamuno, la infinita distancia entre la criatura y el creador no se convierte en maldición, sino en acicate para subir más alto. Si las uvas son inalcanzables siempre cabe decir que están verdes (Nietzsche) o saltar con más ahínco (Unamuno).

"Cristo, el sobre-hombre en arquetipo". Ya hemos visto en el Diario intimo cómo Unamuno interpreta al cristiano como el verdadero sobrehombre, y relaciona los conceptos de sobre-natural y sobre-humanidad. De éste modo, Cristo, que es la manifestación absoluta de lo sobre-natural, se convierte así en el arquetipo de sobrehombre. La maldición que Nietzsche hace de Cristo, el verdadero sobrehombre, es por no poder él mismo ser un sobrehombre.

"Hambre de eternidad fue todo el hipo de tu pobre alma, hasta la muerte triste". El rector de Salamanca trata a todos los autores 
que lee (Schopenhauer, Kant, Spinoza, etc.) bajo el mismo prisma: como un caso concreto del ansia de ser inmortales. No sólo la biografía íntima de los autores, sino también su pensamiento "éxtimo", serían consecuencias de este afán. El hipo de Nietzsche, que puede significar ansia o rabia, lo interpreta Unamuno como ansia de eternidad. La tristeza de la muerte podemos interpretarla en dos sentidos: la muerte en general es triste porque provoca una pérdida irreparable en el mundo (la muerte, desdicha fuerte, que decía Calderón); pero, por otro lado, la muerte de Nietzsche en concreto fue triste por las condiciones de locura en las que llegó a ella.

"A tu atribulado corazón le diste la vuelta eterna, así queriendo el cipo de ultratumba romper". El corazón (centro de la persona) de Nietzsche vive atribulado por el ansia de eternidad, por ello tiene que idear un falso remedo de vida perdurable: la vuelta eterna. El sustantivo "vuelta", demasiado desgastado por el uso cotidiano, hay que tomarlo como participio de "volver"; esta "eterna vuelta" o "eterno volver" es la traducción unamuniana del "eterno retorno", no sólo nietzscheano, sino también platónico. En fin, la vuelta eterna es lo que posibilita romper la estela funeraria (cipo) de ultratumba.

“¡oh nuevo Edipo! víctima de la Esfinje [sic] a que creíste vencer!”. Nietzsche es un nuevo Edipo por haber intentado vencer a la Esfinge. La Esfinge, en Unamuno, es el símbolo de la pregunta fundamental: ¿quién soy yo y qué será de mí? A ella dedicó una obra de teatro y memorables pasajes. Sobre los eruditos (Nietzsche profesor), decía Unamuno que preferían contar las cerdas del rabo de la Esfinge antes que mirarla a la cara. El Nietzsche liberado de sus obligaciones docentes, podemos aventurar, es un hombre que miraba a la Esfinge a la cara, e incluso creyó vencerla con la vuelta eterna; aunque para Unamuno no sea esta una salida racional.

"Sintiéndote por dentro esclavo dominación cantaste". Unamuno no es muy prolijo cuando habla de la moral de señores y 
moral de esclavos de Nietzsche. No parece que fuera uno de los temas que más le interesaran, como podía ser la vuelta eterna o el sobrehombre. Sin embargo, aquí hace una interpretación de la voluntad de poder y la moral de señores de Nietzsche, como surgentes de un sentimiento interno de esclavitud (¿por la imposibilidad de rehuir la muerte?). Quien está en mejores condiciones de cantar a la libertad es el esclavo; si en Nietzsche vibran las páginas cargadas de voluntad de dominio, ¿no será porque se sentía subyugado?, parece apuntar Unamuno.

"Y fue lamento lo que la risa sonó de león bravo". El león de la segunda transformación nietzscheana ríe; pero para Unamuno es ésta una risa que suena a trágico, porque la vuelta eterna no consigue satisfacer al afán de inmortalidad. Unamuno no se detiene en las tres transformaciones; también aquí se queda sólo con la transformación en león, que al fin y al cabo parece la más consonante, a primera vista, con la voluntad de poder. Falta en él una reflexión más profunda sobre la tercera transformación nietzscheana, la transformación en niño; pues hubiera encontrado relaciones con la línea evangélica, o habría encontrado mucha cercanía con reflexiones propias sobre la infancia creadora: "En tanto el niño juega al creador, forjando de todas piezas palabras, creándolas, afirmando la originalidad originaria que para tener más tarde que entenderse con los demás habrá de sacrificar; ejerce la divina fuerza creadora de la niñez, jerga, egregio poeta, con el mundo, crea palabras sin sentido [...] ¿Sin sentido? ¿No empezó así el lenguaje? ¿No fue la palabra primero y su sentido después?” (1902: 77).

"Luchaste con el hado en turbulento querer durar". El hado dicta sentencia de muerte para todo cuanto vive. La vida de Nietzsche, interpretada por Unamuno, fue una lucha constante contra este hado fatídico. Con una expresión gráfica "querer durar", el rector da algunas pistas sobre su concepción de la inmortalidad: es algo que reside en la voluntad, en el querer (en las ganas, diría). 
Por otro lado, no es sólo querer vivir: es querer durar (que es más general que vivir): duran las pirámides aunque no viven... Se diría que las ganas de vivir pertenecen de tal modo al ser humano, que nos conformaríamos con cualquier tipo de eternidad, aunque fuera una eternidad como la de las piedras. Por eso el querer durar es turbulento.

"Para morir al cabo libre de la razón, nuestro tormento". La lucha contra el hado acabó con Nietzsche, al menos así lo interpreta Unamuno (y no sólo él). La muerte de Nietzsche, sumido en la locura, fue sin duda un símbolo para la cultura europea de la crisis finisecular por la que estaban pasando; un caso más del maladie $d u$ siècle. Por eso son significativas las palabras que escoge Unamuno para hablar de la "razón": perder la razón es liberarse; y la razón es nuestro tormento, por ser causa de la enfermedad. Nuestro... ¿De quién? De los europeos cultos del cambio de siglo, si hablamos en particular (Tanganelli, 2001); de todo ser humano en general.

\section{Convergencias y divergencias: concordia discors}

Tracemos, para concluir, algunas convergencias y divergencias entre ambos sentidores. Algunas han sido tratadas por otros autores, otras las presentamos por primera vez. En el plano de las convergencias nos centraremos en la tarea de decirse, la vocación de despertar conciencias, el pensar con el cuerpo o la importancia dada a la psicología de la creencia. En el plano de las divergencias, por otro lado, centraremos la mirada en el sentimiento religioso, la voluntad de poder y el concepto de superhombre.

En ambos autores encontramos una voluntad, no sólo de decir cosas, sino de decir-se a sí mismos. Decir cosas significa hablar de elementos externos a mí, de elementos que no tocan de lleno mi existencia; mientras que decir-me es hablar de modo que mi existencia entera quede implicada. El Ecce Homo, en Nietzsche, sería el 
principal testimonio de esta literatura autoreferencial; aunque en realidad, todas las obras hablan de él, puesto que toda su filosofía es un experimento llevado a cabo en primera persona. Cómo se hace una novela, de Unamuno, quizá sería el testimonio publicado más evidente del decir-se unamuniano. Nótese que el decir-se no tiene nada que ver con el decir-te o el decir-le: yo nunca estoy respecto de mí mismo en la misa posición existencial que respecto a los demás.

Esta tarea de decir-se tiene una finalidad: clarificar la existencia propia; también, tiene una finalidad concomitante: animar a los demás a hacer lo propio. El decir-se no sólo tiene repercusión sobre aquel que se dice, sino también sobre aquellos que escuchan el decir. Tanto Unamuno como Nietzsche tuvieron vocación de "despertar conciencias", a pesar de algunos consejos sobre la soledad de Zaratustra o de don Quijote. Para Unamuno llega a ser la decimoquinta obra de misericordia despertar al dormido; por su lado, en Nietzsche (aunque no como obra compasiva de misericordia) parece latir el interés por despertar la conciencia del prójimo. El modo en que las conciencias se despiertan (a voces, en Unamuno, a martillazos en Nietzsche) es indiferente. La obra de ambos autores es una llamada a empuñar la existencia de modo más auténtico.

¿Cómo es posible decir-se? ¿Cómo lograr que mi pensamiento no sea un pensamiento más que venga a sumarse al cúmulo de pensamientos muertos, pasto de los eruditos? Pensando con el cuerpo, devolviendo el cuerpo al lugar que nunca debería haber abandonado. Quizá en Nietzsche esto llegue a exagerarse al conectar la filosofía alemana con la mala digestión (Nietzsche, 2001: 57), pero en Unamuno lo encontramos formulado con más corrección y verdad en Del Sentimiento Trágico de la Vida: "Hay personas, en efecto, que parecen no pensar más que con el cerebro, o con cualquier otro órgano que sea el específico para pensar; mientras otros piensan con todo el cuerpo y toda el alma, con la sangre, con el tuétano de 
los huesos, con el corazón, con los pulmones, con el vientre, con la vida"; o este otro: "Y haga lo que quiera, filosofa, no con la razón sólo, sino con la voluntad, con el sentimiento, con la carne y con los huesos, con el alma toda y con el cuerpo. Filosofa el hombre" (Unamuno, 2005: 131). Nietzsche, por su parte, apela a la gran razón del cuerpo, para explicar la compleja vida del hombre: "No somos ranas pensantes, aparatos de objetivar y registrar con entrańas puestas en conserva; tenemos que dar a luz constantemente nuestros pensamientos desde nuestro dolor y proporcionarles maternalmente cuanto tengamos en nosotros de sangre, corazón, fuego, placer, tormento, conciencia, destino y fatalidad" (Nietzsche, 2002: 37)

De hecho, Nietzsche intenta operar una inversión radical en la filosofía, explicando las cosas más altas por las más bajas, en lugar de hacerlo al revés, como era propio del idealismo. Este explicar lo alto por lo bajo, se lleva a cabo, entre otras cosas, con una labor de psicología de la creencia. La psicología de la creencia es, precisamente, una idea que comparten ambos autores, aunque con sentido diverso. Nietzsche, como psicólogo -título que preferiría al de filósofo- (Nietzsche, 2001: 92) intenta sacar a la luz las motivaciones ocultas que llevan a los hombres a creer en Dios: básicamente, para poder mantener a raya a los señores ávidos de poder. Pretende, con ello, haber puesto de manifiesto la irracionalidad de la creencia. Unamuno, ejerciendo de psicólogo de la creencia, dice también en Del sentimiento trágico de la vida, que "la ciencia de la religión, por otra parte, de la religión como fenómeno psíquico individual y social sin entrar en la validez objetiva trascendente de las afirmaciones religiosas, es una ciencia que, al explicar el origen de la fe en que el alma es algo que puede vivir separado del cuerpo, ha destruido la racionalidad de esta creencia”. A nuestro entender, ambos erran en el diagnóstico, puesto que los motivos que llevan a uno a creer o no, no tienen nada que ver con la realidad de lo creído. El plano de la psicología no es el plano de la ontología; el 
contexto del descubrimiento no tiene por qué interferir en el contexto de justificación.

Sin embargo, aunque ambos comparten algo de esta psicología de la creencia (en Nietzsche mucho más acusadamente que en Unamuno), en el valor de la creencia religiosa en sí difieren profundamente. Así, dice Nietzsche que "Dios, inmortalidad del alma, redención, más allá, son conceptos a los que no he concedido ninguna atención ni ningún tiempo, ni siquiera cuando era niño-¿Quizá nunca he sido lo suficientemente infantil para ello?” (Nietzsche, 2001: 55). Más adelante: “Qué sentido tienen todos aquellos conceptos mentira, los conceptos-mentira, los conceptos auxiliares de la moral, alma, espiritu, libre voluntad, Dios, sino aquel de arruinar psicológicamente a la humanidad?" (128), y aún: "El concepto de más allá, de mundo verdadero, inventado para desvalorizar el único mundo que existe" (180). Pero esto contrasta profundamente con las opiniones del rector de Salamanca respecto a la creencia religiosa. Valorando la creencia religiosa, al contrario que Nietzsche y a propósito de él, dice Unamuno: "Desgraciado el pueblo al que no le dejan soñar con los ojos puestos en el cielo de la noche y morando más allá de las últimas estrellas" (1915). Baste comprobar el profundo respeto con que trata el tema en San Manuel Bueno, Mártir; en cuyo trasfondo hay una curiosa relación con Nietzsche. Cuenta, en una carta a su amigo Ilundain, cómo había podido comprobar de primera mano el efecto nocivo de Nietzsche en algunos sacerdotes: "Empezó por uno que vino a mi casa a verme, cuando se hallaba en las garras de Nietzsche, nietzschenizado por completo (...) Ofrece un caso típico y trágico de lucha entre su corazón y su cabeza, un ejemplar de cura sin fe. Y empezando por él he venido a dar en director espiritual de algunos curas jóvenes que sienten que se les va la fe católica” (Unamuno, 1996: 182). En el fondo, si para Nietzsche la religión (en concreto la cristiana) es el último producto de la degeneración decadente del hombre, para Unamu- 
no es uno de los productos (sit venia verbo) más hermosos de la humanidad, que le ha proporcionado mayores consuelos.

La religión es interpretada por ambos autores desde sus posiciones respecto a la tendencia humana fundamental: el poder (Nietzsche) o la vida (Unamuno). Las religiones se han constituido como super-organismos de la voluntad de poder, al servicio de los más débiles (Nietzsche) o las religiones responden al anhelo fundamental de vivir por siempre (Unamuno). La tendencia fundamental para Unamuno no podría ser, de ninguna manera, voluntad de poder, sino voluntad de vivir. Los jóvenes ańos socialistas y el cristianismo cordial le hacían incapaz de simpatizar con la moral de los seńores. Del mismo modo, quizá la voluntad de vivir unamuniana habría sido interpretada por Nietzsche (si lo hubiera conocido) como un rasgo más de una mala finitud asimilada.

En el fondo, como en todo, late una divergencia también en cuanto a la concepción del hombre: mientras que para el Zaratustra nietzscheano el hombre es algo que debe ser superado, el Quijote unamuniano se esfuerza por ser "nada menos que todo un hombre" (Unamuno, 1995). A modo de breve crítica: el sobrehombre de Nietzsche, ¿no es acaso un nuevo más allá, una nueva meta, un nuevo ideal, que descentra al hombre de sí mismo y lo aliena buscando su esencia en algo que no es él mismo? Si así fuera, parece más plena de sentido y menos alienante la propuesta unamuniana de ser nada menos que todo un hombre.

\section{Conclusión}

Hemos reseñado, en primer lugar, y de modo muy sintético, los estudios que han tratado la relación de ambos autores, estableciendo así un status quaestionis desde el cual se podría hacer nuestra aportación. En segundo lugar, recurriendo a las propias fuentes, hemos evidenciado cómo antes del destierro Unamuno apenas conoce a 
Nietzsche por no haberlo leído directamente, cosa que cambia tras el destierro, y sin que pueda llegar a decirse que Nietzsche fuera una lectura recurrente de Unamuno (o no más que otros tantos autores que pueblan los escritos del pensador vasco). En un tercer momento, hemos trazado la imagen que Unamuno tenía de Nietzsche, recurriendo al Diario intimo (y el concepto de sobrehombre), dos artículos (y el supuesto antigermanismo y seguro anticristianismo), el trabajo extenso Del sentimiento trágico de la vida (y el concepto de la vuelta eterna) y, por último, un poema que condensa todas estas ideas. En cuarto y último lugar hemos apuntado las convergencias (decirse, despertar conciencias, pensar con el cuerpo, la psicología de la fe) y divergencias (el sentimiento religioso, la voluntad de poder y el superhombre) de estos dos autores.

Concluimos con un resumen de Pedro Cerezo Galán y que sintetiza perfectamente las posturas del Quijote (Unamuno) y de Zaratustra (Nietzsche). ¿Qué cabe hacer ante la finitud radical que nos aqueja? Apostar, diría el hermano Pascal; jugar, replicaría el pobre Nietzsche; luchar, sentenciaría el hombre don Miguel de Unamuno (Cerezo Galán, 1996: 424).

\section{Bibliografía}

Barrenechea, Mariano A., 1915, Ensayo sobre Federico Nietzsche, Buenos Aires, Nosotros.

Brandes, Georg, 1914, Essais Choisis, Renan, Taine, Nietzsche, Heine, Kielland, Ibsen, París, Mercure de France.

Cerezo Galán, Pedro, 1996, Las máscaras de lo trágico, Filosofia y tragedia en Miguel de Unamuno, Madrid, Trotta.

Cordero, Miguel Ángel, 2003, “¿Tragedia o tortura en 'El sentimiento trágico de la vida' de Miguel de Unamuno?”, en Cua- 
dernos de la Cátedra Miguel de Unamuno, núm. XXXVIII, pp. 13-28.

García Morente, Manuel, 1938, Idea de la Hispanidad, II, Simbolización del estilo español, Alianza Editorial, disponible en: http:// www.filosofia.org/his/h1938a1.htm (consultado: 19/I/2015).

Gillis, Caroline, 2008, "Unamuno y Nietzsche: Una oposición insuperable", en Cuadernos de la Cátedra Miguel de Unamuno, núm. XLVI, pp. 45-57.

González Urbano, Eulalia, 1986, "Visión trágica de la filosofía: Unamuno y Nietzsche", Logos: Anales del Seminario de Metafisica, núm. 21, pp. 13-40.

Izquierdo Sánchez, Agustín, 1992, Nietzsche y Unamuno: vida y saber, Madrid, Mare Nostrum.

Lavoie, Charles Auguste, 1976, "Unamuno et Nietzsche, oul'amitiéavortée", en Cuadernos de la Cátedra Miguel de Unamuno, núm. XXIV, pp. 105-118.

Mendoza Negrillo, Jesús, 1983, "Unamuno ante la voluntad de poder nietzscheana", en Cuadernos de la cátedra Miguel de Unamuno, núm. XXVII-XXVIII, pp. 59-81.

Nietzsche, Friedrich, 1919?, Epistolario inédito, Madrid, Biblioteca nueva. , 1921, Ecce Homo, suivi des Poesies, Paris, Mercure de France. , 1923, Sanint Janvier, suivi de quelques aphorismes, Delamain, Boutelleau, París, Librarie Stock. , 2001, Ecce Homo, Madrid, Alba. , 2002, La gaya ciencia, Madrid, Edaf.

Ribas, Pedro, 1987, "Unamuno y Nietzsche", en Cuadernos hispanoamericanos, núm. 440-44, pp. 251-282 (es parte de su tesis doctoral no publicada de 1976).

Sobejano, Gonzalo, 1967, Nietzsche en España, Madrid, Gredos. 
Tamayo Alfredo, 2000, "Presencia de Federico Nietzsche en Miguel de Unamuno: En el centenario de la muerte de F. N. (1900-2000)", Boletín de la Real Sociedad Bascongada de Amigos del País, 56, núm. 2, pp. 617-631.

Tanganelli, Paolo, 2001, Hermenéutica de la crisis en la obra de Unamuno entre finales del XIX y comienzos del XX: la crisis del 97 como posible exemplum de la crisis finisecular, Salamanca, Ediciones Universidad de Salamanca, disponible en: http://gredos. usal.es/jspui/handle/10366/55593 (consultado: 19/I/2015).

Torre Ruiz, Hilario Andrés, 1907, Federico Nietzsche, Valladolid, Imprenta Castellana.

Unamuno, Miguel de, 1902, Amor y Pedagogía, Barcelona, Imprenta de Henrich.

, 1911, "Soneto a Nietzsche", Revista Contemporánea, Santiago de Chile.

, 1915, "Algo sobre Nietzsche", en La Nación, Buenos Aires, 5 de Mayo, disponible en: http://gredos.usal.es/jspui/ bitstream/10366/80645/1/CMU_4-114.pdf (consultado el 19/I/2015).

, 1919, "Para qué escribir", Nuevo Mundo, 18 de Julio, Madrid, disponible en: http://gredos.usal.es/jspui/bitstream/10366/81033/1/CMU_6-117.pdf (consultado el $19 / \mathrm{I} / 2015)$.

, 1972, Cartas inéditas de Miguel de Unamuno, Sergio Fernández (comp., pról.), Madrid, Rodas.

, 1996, Epistolario americano, (1890-1936), Salamanca, Universidad de Salamanca. , 2005, Del sentimiento trágico de la vida, Madrid, Tecnos. , 2005, Diario intimo, en Obras Completas, vol. VII, Fundación A. Castro. , 2007, Obras Completas, vol. VIII, Fundación A. Castro. 
, 2012, Cartas del destierro, entre el odio y el amor, 19241930, Salamanca, Universidad de Salamanca.

, 2012, Diario intimo (1987), E. González (ed.), Salamanca, Universidad de Salamanca.

Zweig, Stefan, 1930, Le combat avec le démon, Nietzsche (18441900), París, Librarie Stock.

Recibido: 6 de mayo de 2016 Aceptado: 5 de noviembre de 2016 